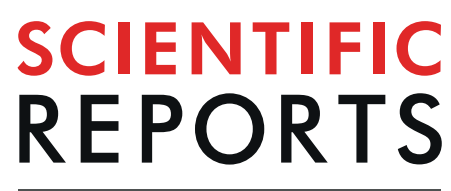

natureresearch

\title{
Global phylogeography and genetic diversity of the long-finned pilot whale Globicephala melas, with new data from the southeastern Pacific
}

\begin{abstract}
Sebastián Kraft $\mathbb{D}^{1}$, MJosé Pérez-Álvarez ${ }^{1,2,3^{*}}$, Carlos Olavarría ${ }^{2,4}$ \& Elie Poulin $\mathbb{D}^{1}$
The matrilineal long-finned pilot whale presents an antitropical distribution and is divided into two subspecies, one in the temperate seas of the Southern Hemisphere and the other restricted to the North Atlantic and Mediterranean. Until now, population genetic and phylogeographic studies have included localities of most of its Northern Hemisphere distribution, while only the southwestern Pacific has been sampled in the Southern Hemisphere. We add new genetic data from the southeastern Pacific to the published sequences. Low mitochondrial and nuclear diversity was encountered in this new area, as previously reported for other localities. Four haplotypes were found with only one new for the species. Fifteen haplotypes were detected in the global dataset, underlining the species' low diversity. As previously reported, the subspecies shared two haplotypes and presented a strong phylogeographic structure. The extant distribution of this species has been related to dispersal events during the Last Glacial Maximum. Using the genetic data and Approximate Bayesian Calculations, this study supports this historical biogeographic scenario. From a taxonomic perspective, even if genetic analyses do not support the subspecies category, this study endorses the incipient divergence process between hemispheres, thus maintaining their status and addressing them as Demographically Independent Populations is recommended.
\end{abstract}

Cetaceans have a diverse -and many times contrasting- array of geographic distributions. Some of the widest ranging species include the cosmopolitan sperm whale Physeter macrocephalus ${ }^{1}$ and the orca Orcinus orca ${ }^{2}$. Other species, especially small-sized odontocetes, generally present coastal and more restricted distributions, like the extreme case of the vaquita, Phocoena sinus ${ }^{3}$.

Some cetaceans have a particular distribution pattern known as disjunct or antitropical, in which the taxon is present at high latitudes in both hemispheres while being absent from lower latitudes ${ }^{4}$. Examples include the mysticete genus Eubalaena, with E. borealis inhabiting the North Pacific, E. japonica the North Atlantic and their austral equivalent in the Southern Hemisphere, E. australis ${ }^{5}$. The phocoenid species pair Phocoena phocoena and P. spinipinnis is another example, found in the Northern Hemisphere and the coasts of South America, respectively ${ }^{6}$. Among delphinids, the two Lissodelphis species also present this antitropical distribution pattern; $L$. peronii is present around the Southern Hemisphere, while L. borealis is found in the North Pacific ${ }^{7}$. A similar antitropical distribution is presented by the two subspecies of long-finned pilot whales Globicephala melas, where $G$. m. edwardii inhabits the temperate to subpolar waters of the Southern Hemisphere, while G. m. melas is restricted to the North Atlantic ${ }^{8}$. Extinct populations of long-finned pilot whales have been reported in the North Pacific, from Japan ${ }^{9}$ and Alaska ${ }^{10}$, dating back $8000-12000$ years and $2500-3500$ years, respectively ${ }^{9,10}$.

Pilot whales are a highly social matrilineal odontocete, thought to be among the most gregarious cetaceans. The species is known to form groups with a mean size around tens of individuals ${ }^{11}$ that can increase to hundreds

${ }^{1}$ Instituto de Ecología y Biodiversidad, Laboratorio de Ecología Molecular, Departamento de Ciencias Ecológicas, Facultad de Ciencias, Universidad de Chile, Santiago, Chile. ${ }^{2}$ Centro de Investigación Eutropia, Santiago, Chile. ${ }^{3}$ Escuela de Medicina Veterinaria, Facultad de Ciencias, Universidad Mayor, Santiago, Chile. ${ }^{4}$ Centro de Estudios Avanzados en Zonas Áridas (CEAZA), La Serena, Chile. *email: maria.perez@umayor.cl 


\begin{tabular}{|l|l|l|l|l|l|l|l|l|l|l|l|l|l|l|l|l|l|l|l|l|l|}
\hline & S+R & $\mathbf{P}+\mathbf{U}$ & $\mathbf{Q}+\mathbf{Y}$ & $\mathbf{R} 2$ & $\mathbf{T}$ & $\mathbf{O}$ & $\mathbf{V}$ & $\mathbf{O} 2$ & $\mathbf{W}$ & $\mathbf{Z}$ & $\mathbf{E}+\mathbf{G}$ & $\mathbf{6 0}$ & $\mathbf{6 2}$ & $\mathbf{X}$ & $\mathbf{D}$ & Total & $\mathbf{h}$ & $\mathbf{S}$ & $\mathbf{H d}$ & $\boldsymbol{\pi} \%$ & $\mathbf{\Pi}$ \\
\hline TAS & 51 & 32 & 72 & & & & & & & & & & & & & 215 & 6 & 4 & 0.783 & 0.394 & 1.356 \\
\hline NZ & 6 & 333 & 3 & & 1 & 14 & 1 & & & & & & & & & 358 & 6 & 5 & 0.133 & 0.040 & 0.136 \\
\hline CL & 31 & 45 & 12 & 2 & & & & & & & & & & & & 90 & 4 & 4 & 0.620 & 0.230 & 0.791 \\
\hline NWA & 73 & 1 & & & & & & & & & & & & 4 & & 78 & 3 & 2 & 0.123 & 0.064 & 0.220 \\
\hline FI & 55 & 17 & & & & & & & & & & & & & & 72 & 2 & 1 & 0.365 & 0.100 & 0.365 \\
\hline UK & 34 & 1 & & & & & & & & & 4 & & & & & 39 & 3 & 2 & 0.235 & 0.070 & 0.240 \\
\hline IB & 39 & & & & & & & & & & 1 & 1 & 1 & & & 42 & 4 & 3 & 0.139 & 0.055 & 0.188 \\
\hline NEA & 20 & & & & & & & & & & 1 & & & & & 21 & 2 & 1 & 0.095 & 0.027 & 0.095 \\
\hline GIB & 44 & & & & & & & & & & & & & & 20 & 64 & 2 & 1 & 0.436 & 0.126 & 0.436 \\
\hline MED & 12 & & & & & & & & & & & & & & 21 & 33 & 2 & 1 & 0.477 & 0.138 & 0.477 \\
\hline G. m. edwardii & 88 & 410 & 87 & 2 & 1 & 14 & 1 & 14 & 15 & 31 & 6 & & & & & 663 & 10 & 9 & 0.580 & 0.233 & 0.802 \\
\hline G. m. melas & 277 & 19 & & & & & & & & & & 1 & 1 & 4 & 41 & 349 & 8 & 5 & 0.353 & 0.117 & 0.404 \\
\hline Total & 365 & 429 & 87 & 2 & 1 & 14 & 1 & 14 & 15 & 31 & 6 & 1 & 1 & 4 & 41 & 1012 & 15 & 12 & 0.680 & 0.264 & 0.909 \\
\hline
\end{tabular}

Table 1. Summary of number of haplotypes and genetic indices for each included locality and per subspecies (abbreviations are detailed in the methods section). The first row indicates the names of each haplotype according to the original authors. Numbers 60 and 62 represent the two last digits of the GenBank codes provided by Miralles et al., (2016) for identification. Number of haplotypes (h), haplotype diversity (Hd), pairwise differences between sequences $(\Pi)$ and nucleotide diversity $(\pi)$ are also detailed.

through aggregations ${ }^{12,13}$. These groups are structurally based on strong matrilineal associations $s^{6,8}$ of closely related females and their descendants ${ }^{14}$. Pilot whales are among the most common cetaceans involved in mass strandings $s^{6,8,13}$. Southern Hemisphere long-finned pilot whales were originally described as a distinct species, $G$. leucosagmaphora ${ }^{15}$, but eventually ranked as one of the two subspecies of $G$. melas ${ }^{16}$, based on observations of the coloration pattern and morphology ${ }^{16,17}$. Sergeant (1962) stated that he found only minor differences in coloration and none in external morphology between specimens from the two hemispheres, albeit being in agreement with the subspecies classification proposed by Davies $(1960)^{16}$. The author also expressed the need of including samples from additional localities, in order to assess the variation of the colour pattern in the subspecies, as also recommended by other authors ${ }^{18}$. A more recent study found differences in skull morphometry of North and South Atlantic specimens ${ }^{19}$, but no studies were found that account for geographic variation within each area. Little genetic evidence exists to support their classification status using mitochondrial DNA. Oremus et al., (2009) performed the first inter-hemisphere comparison of the taxa, between the southwestern Pacific and the North Atlantic ${ }^{20}$. The authors also stated that the two subspecies do not qualify as Evolutionary Significant Units (ESU) according to the reciprocal monophyly criterion of Moritz $(1994)^{21}$, only reporting restrictions to gene flow among the areas of distribution mainly based on differences in the frequency of shared haplotypes. In the study of Oremus et al., (2009), preliminary genetic data support a biogeographic scenario previously proposed by Davies $(1960)^{22}$. A colonization event from south to north would have taken place through a founder effect, followed by demographic population growth. Additional genetic research on pilot whales has been conducted mostly at the population level in the North Atlantic and Mediterranean Sea ${ }^{23-25}$, however, an integration of this available information is missing, together with the sampling of other areas such as the southeastern Pacific.

In this study, we include new genetic data and results from samples collected in two mass standings in southern Chile, in order to improve the global phylogeographic overview of long-finned pilot whales. We also evaluate the historical biogeographic processes that originated the extant antitropical distribution of this species and discuss its taxonomic status.

\section{Results}

Southeastern pacific sampling and genetic diversity. In total, $90 \mathrm{mtDNA}$ sequences were obtained, defining four haplotypes. One haplotype was previously unreported (hereon referred to as haplotype R2). Haplotype and nucleotide diversities were low: $\mathrm{Hd}=0.62$ and $\pi=0.23 \%$ (Table 1 ).

Microsatellites were successfully genotyped in $n=44$ samples ( 32 from Isla Clemente and 12 from Isla Navarino), across fourteen polymorphic loci. DlrFCB6, and GT51 presented an excess of homozygotes, but were not used in the comparisons among hemispheres. Regional diversity values of usable loci were $H_{o}=0.655$; $H_{e}=0.700$ and $\mathrm{nA}=7.5$ (Table 2).

Global diversity analysis. After adding previously published sequences from other oceanic basins ${ }^{20,23-26}$, a total of 15 haplotypes were obtained after the elimination of the site that was generating phylogeographic noise in the total 1012 sequences. This led to the combination of four previously described haplotypes in the following pairs: S with R, P with U, Q with Y, and E with G (Table 1). Nine of the twelve haplotypes reported by Miralles et al., (2016), originally of a consensus fragment size of $703 \mathrm{bp}$, were also merged into haplotype $\mathrm{S}+\mathrm{R}$.

Global and local haplotype networks. Adding previously published sequences from other oceanic basins, we detected that (1) two haplotypes were shared between G. m. edwardii (SP) and G. m. melas (NA and MED), and (2) one haplotype was shared by all SP localities but was absent from NA and MED (Table 1, Fig. 1). 


\begin{tabular}{|c|c|c|c|c|c|c|c|c|c|c|c|c|}
\hline \multirow[b]{2}{*}{ Locus } & \multicolumn{4}{|c|}{ Tasmania \& New Zealand } & \multicolumn{4}{|c|}{ Chile } & \multicolumn{4}{|c|}{ North Atlantic } \\
\hline & $\mathbf{n}$ & Alleles & $H_{o}$ & $H_{e}$ & $\mathbf{n}$ & Alleles & $H_{o}$ & $H_{e}$ & $\mathbf{n}$ & Alleles & $H_{o}$ & $\mathrm{H}_{\mathrm{e}}$ \\
\hline $409 / 470$ & 262 & 10 & 0.844 & 0.825 & - & - & - & - & 529 & 9 & - & 0.567 \\
\hline $415 / 416$ & 242 & 9 & 0.798 & 0.801 & - & - & - & - & 529 & 5 & - & 0.567 \\
\hline $464 / 465$ & 122 & 9 & 0.648 & 0.681 & 44 & 9 & 0.676 & 0.578 & 529 & 6 & - & 0.670 \\
\hline DlrFCB1 & 264 & 15 & 0.777 & 0.774 & 44 & 8 & 0.682 & 0.760 & - & - & - & - \\
\hline DlrFCB6 & 256 & 7 & 0.672 & 0.693 & 44 & 7 & 0.476 & 0.716 & - & - & - & - \\
\hline EV1 & 262 & 14 & 0.756 & 0.773 & 44 & 10 & 0.756 & 0.739 & - & - & - & - \\
\hline EV37 & 263 & 10 & 0.814 & 0.775 & 44 & 15 & 0.633 & 0.858 & 529 & 6 & - & 0.748 \\
\hline EV94 & 255 & 7 & 0.620 & 0.686 & - & - & - & - & 529 & 7 & - & 0.772 \\
\hline GT23 & 263 & 5 & 0.468 & 0.439 & 44 & 4 & 0.341 & 0.567 & - & - & - & - \\
\hline GT39 & 122 & 10 & 0.787 & 0.822 & 44 & 5 & 0.636 & 0.512 & - & - & - & - \\
\hline GT51 & 253 & 3 & 0.300 & 0.308 & 44 & 4 & \begin{tabular}{|l|}
0.318 \\
\end{tabular} & 0.492 & - & - & - & - \\
\hline GT575 & 254 & 11 & 0.827 & 0.836 & 44 & 7 & 0.841 & 0.828 & - & - & - & - \\
\hline MK5 & 244 & 6 & 0.623 & 0.658 & 44 & 7 & 0.682 & 0.670 & - & - & - & - \\
\hline MK9 & 120 & 4 & 0.625 & 0.618 & 44 & 4 & \begin{tabular}{|l|}
0.591 \\
\end{tabular} & 0.613 & - & - & - & - \\
\hline PPHO131 & 248 & 10 & 0.734 & 0.745 & 44 & 6 & 0.714 & 0.696 & - & - & - & - \\
\hline
\end{tabular}

Table 2. Comparisons among shared microsatellite loci from three studies including Tasmania and New Zealand ${ }^{27}$, Chile (this study) and the North Atlantic ${ }^{28}$. Dashes indicate either unreported information or no locus amplification.

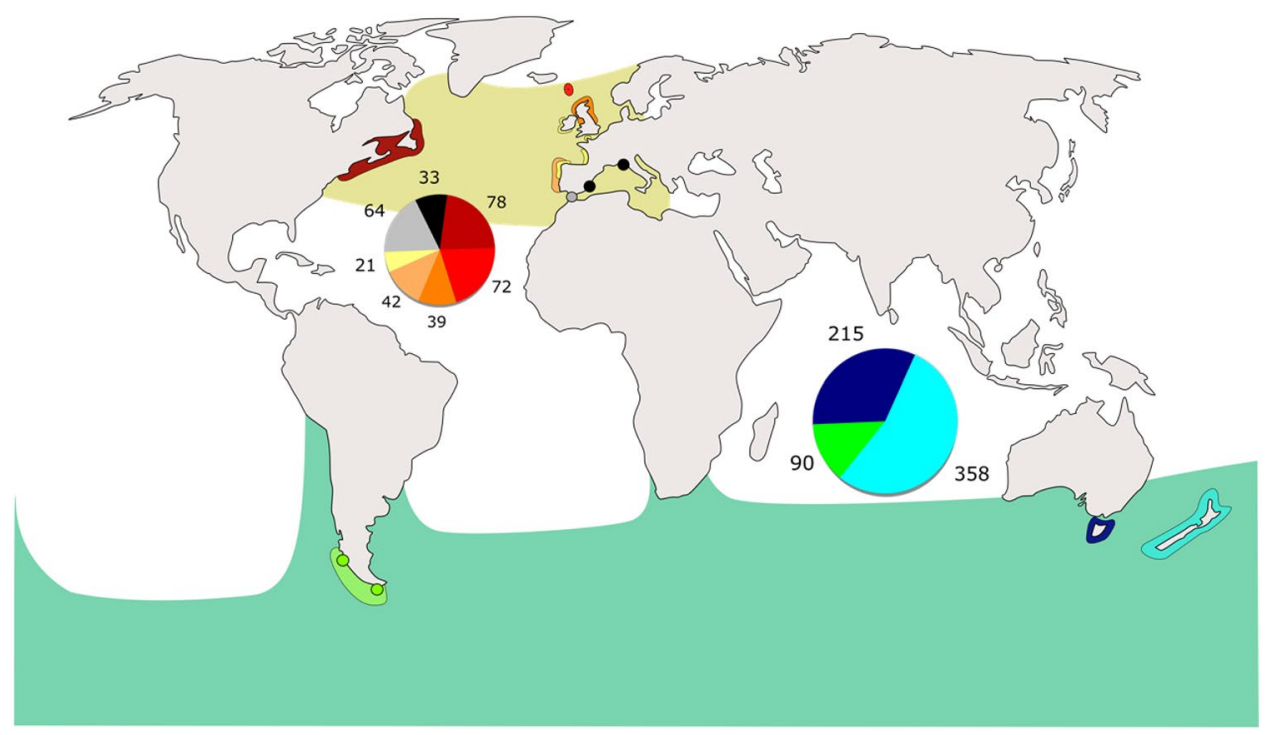

Figure 1. Origin of the 1012 sequences included in the study: Chile (green), Tasmania (dark blue), New Zealand (light blue), northwestern Atlantic (dark red), Faroe Islands (red), United Kingdom (orange), Iberian Peninsula (light orange), northeastern Atlantic (yellow), Strait of Gibraltar (grey), Mediterranean (black). Pie charts indicate the number of sequences contained in each locality. Ocean areas in yellow represent the extant distribution of G. m. melas and in green of G. m. edwardii. Map adapted from SVG SILH (https://svgsilh.com/ image/306338.html), released as public domain under Creative Commons CC0 1.0. Figure generated by S.K. in Inkscape 0.92.4 (https://www.inkscape.org).

Haplotypes $\mathrm{P}+\mathrm{U}$ and $\mathrm{S}+\mathrm{R}$ were the only ones detected within the distribution range of both $G$. melas subspecies (Table 1, Fig. 2a): haplotype $\mathrm{P}+\mathrm{U}$ is present in the $\mathrm{SP}$ and $\mathrm{NA}$, while $\mathrm{S}+\mathrm{R}$ was found in all three basins (SP, NA and MED), and was pivotal in the development of local diversity. Haplotype Q + Y was shared by all SP localities, but absent from NA and MED. The remaining 12 haplotypes represent in situ diversification within each corresponding basin: eight for SP, four for NA and one for MED. The haplotypes found in the Mediterranean area are represented either by $S+R$ or by $D$, which derives directly from it. The same occurs with half (2) of haplotypes encountered in the NA and half (4) of those exclusive to the SP.

In the haplotype network by locality, haplotype $S+R$ is present in all ten studied areas and originates much of the local diversity within them (Table 1, Fig. 2b). Haplotype $\mathrm{P}+\mathrm{U}$ plays a similar, but downscaled role, in the South Pacific; it originates half (4) of the diversity that is exclusive to this area. This haplotype is also much more abundant in the localities corresponding to G. m. edwardii than in the range of G. m. melas, where it was detected 
a.

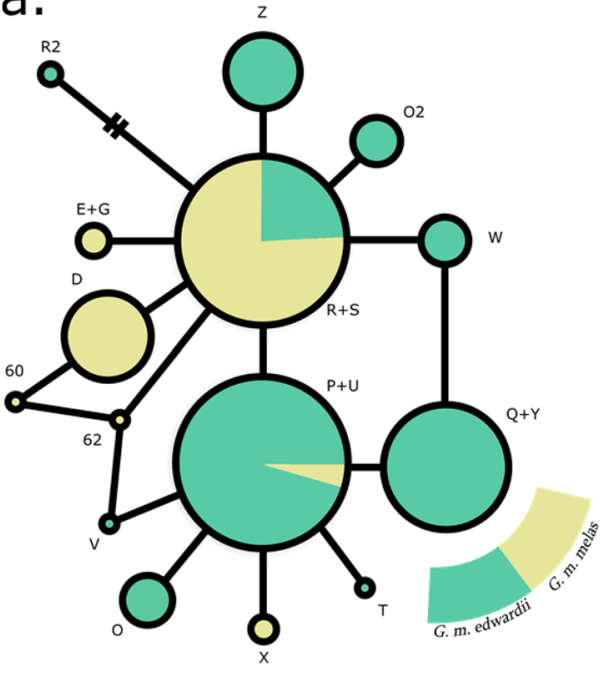

b.

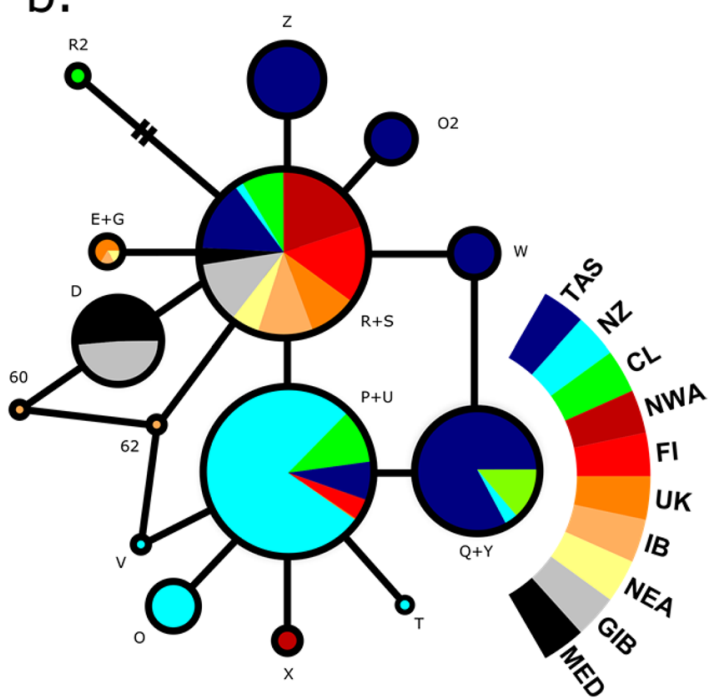

Figure 2. Haplotype networks of (a) the global data coloured by subspecies: G. m. melas in yellow and G. $m$. edwardii in green; and (b) coloured by locality: Tasmania (TAS), New Zealand (NZ), Chile (CL), northwestern Atlantic (NWA), Faroe Islands (FI), United Kingdom (UK), Iberian Peninsula (IB), northeastern Atlantic (NEA), Strait of Gibraltar (GIB) and the Mediterranean Sea (MED). Smallest circle size indicates a frequency of one sequence. Detailed haplotype frequencies can be found in Table 1.

in lower numbers in three localities (17 samples from FI, one from NWA and one from UK). One of the haplotypes that originates from $\mathrm{P}+\mathrm{U}$, haplotype $\mathrm{Q}+\mathrm{Y}$, is exclusive to the South Pacific and is present in all three localities. Ten of the total fifteen haplotypes (67\%) were exclusively present in one of the following five localities: TAS (3), NZ (3), CL (1), IB (2) and NWA (1). In the South Pacific, 70\% of haplotypes were private to one of the three localities; it was the only basin with at least one private haplotype in each. Three private haplotypes were encountered in the North Atlantic: one in the NWA and two in the IB.

Global and local genetic structure. Significant genetic and phylogeographic structure was also detected between the subspecies, i.e. South Pacific with North Atlantic and Mediterranean $\left(F_{S T}=0.439, \varphi_{S T}=0.464\right.$, both $\mathrm{P}<0.000004)$. The Snn test for genetic differentiation was statistically significant among the two disjoint distribution areas of the two subspecies (i.e. G. m. edwardii and G. m. melas; $\mathrm{Snn}=0.830, \mathrm{P}<0.001$ ). Subsequently, samples were organized in this same way for the AMOVA. Similar structure results were obtained grouping the samples by the 10 worldwide localities. Average $\varphi_{S T}$ values were highest within the SP (avg. $\varphi_{S T}=0.283$ ), lowest in the NA (avg. $\varphi_{S T}=0.06$ ), and intermediate among the two Mediterranean localities (avg. $\left.\varphi_{S T}=0.174\right)$ (Table 3). All $\varphi_{S T}$ comparisons were statistically significant within the South Pacific. In the North Atlantic, only the Faroe Islands showed a statistically significant phylogeographic structure with all other localities, while NWA did with FI and UK. All comparisons among localities from different basins showed statistically significant differences. The AMOVA showed significant differentiation among the two distribution ranges, with greater variation among groups than within them (Table 4).

In the Correspondence Analysis, the first axis separated the localities according to their respective hemisphere of origin. The three South Pacific localities (TAS, NZ and CL) were clustered separately from those of the Northern Hemisphere. The second axis divided the Strait of Gibraltar and the Mediterranean Sea from the remaining localities in the Northern Hemisphere (Fig. 3). The calculation of Nei's (1987) net nucleotide divergence $\left(d_{A}\right)$ among the subspecies G. m. edwardii and G. m. melas resulted in $d_{A}=0.00158(\mathrm{SD}=0.00019)$.

Historical biogeography. The origin of the current disjunct distribution of Globicephala melas was explored with DIYABC, using two historical biogeographic models associated to the Last Glacial Maximum (LGM). The first model, scenario 1, represented a colonization event from the Southern Hemisphere to the Northern Hemisphere, followed by isolation and population growth in the Northern Hemisphere. The second model, scenario 2, tested a possible event of vicariance among both distributions.

Based on the genetic data provided, both scenarios were realistic (Fig. 4a), even though the simulations performed were more supportive of the founder effect population history scenario (Fig. 4b). Parameter estimations fell within the proposed ranges and the prior and posterior values from our dataset were not statistically different from simulations. A range expansion would have occurred around 12900 years ago (t2), followed by a distribution split and population growth, 9380 years ago (t1) (Fig. 4c). The mutation rate was estimated at $\mathrm{u}=4.44 \mathrm{e}^{-8}$.

Microsatellite diversity. Previous data on microsatellite diversity was available for the southwestern Pacific $^{27}$ and the North Atlantic ${ }^{23,25,28}$. The diversity by locus reported ${ }^{27,28}$ is shown in Table 2, with five loci in common to both studies. The number of alleles for each shared locus were, respectively: 409/470 (10 vs. 9), 415/416 (9 vs. 5), 464/465 (9 vs. 6), EV37 (10 vs. 6) and EV94 (7 vs. 7). Two of these loci were also present in 


\begin{tabular}{|l|l|l|l|l|l|l|l|l|l|l|}
\hline FST & NWA & FI & UK & IB & NEA & GIB & MED & TAS & NZ & CL \\
\hline NWA & - & 0 & 0.057 & 0.394 & 0.616 & 0 & 0 & 0 & 0 & 0 \\
\hline FI & 0.136 & - & 0.019 & 0.001 & 0.034 & 0 & 0 & 0 & 0 & 0 \\
\hline UK & 0.034 & 0.077 & - & 0.270 & 0.559 & 0.001 & 0 & 0 & 0 & 0 \\
\hline IB & -0.001 & 0.115 & 0.006 & - & 0.999 & 0 & 0 & 0 & 0 & 0 \\
\hline NEA & -0.007 & 0.109 & -0.009 & -0.030 & - & 0.006 & 0 & 0 & 0 & 0 \\
\hline GIB & 0.226 & 0.156 & 0.150 & 0.184 & 0.172 & - & 0.003 & 0 & 0 & 0 \\
\hline MED & 0.615 & 0.430 & 0.486 & 0.552 & 0.524 & 0.174 & - & 0 & 0 & 0 \\
\hline TAS & 0.345 & 0.234 & 0.281 & 0.314 & 0.306 & 0.242 & 0.273 & - & 0 & 0 \\
\hline NZ & 0.865 & 0.751 & 0.844 & 0.863 & 0.869 & 0.798 & 0.811 & 0.513 & - & 0 \\
\hline CL & 0.435 & 0.199 & 0.337 & 0.388 & 0.368 & 0.301 & 0.358 & 0.116 & 0.399 & - \\
\hline 'ST & & & & & & & & & & \\
\hline NWA & - & 0.002 & 0.030 & 0.058 & 0.145 & 0 & 0 & 0 & 0 & 0 \\
\hline FI & 0.089 & - & 0.002 & 0.001 & 0.010 & 0 & 0 & 0 & 0 & 0 \\
\hline UK & 0.043 & 0.131 & - & 0.091 & 0.693 & 0.001 & 0 & 0 & 0 & 0 \\
\hline IB & 0.029 & 0.151 & 0.02 & - & 0.891 & 0.001 & 0 & 0 & 0 & 0 \\
\hline NEA & 0.016 & 0.137 & -0.018 & -0.014 & - & 0.001 & 0 & 0 & 0 & 0 \\
\hline GIB & 0.239 & 0.267 & 0.218 & 0.190 & 0.200 & - & 0.003 & 0 & 0 & 0 \\
\hline MED & 0.578 & 0.530 & 0.538 & 0.540 & 0.544 & 0.174 & - & 0 & 0 & 0 \\
\hline TAS & 0.253 & 0.178 & 0.248 & 0.260 & 0.239 & 0.307 & 0.394 & - & 0 & 0 \\
\hline NZ & 0.849 & 0.762 & 0.864 & 0.873 & 0.878 & 0.855 & 0.893 & 0.421 & - & 0 \\
\hline CL & 0.392 & 0.219 & 0.382 & 0.407 & 0.378 & 0.441 & 0.534 & 0.086 & 0.342 & - \\
\hline
\end{tabular}

Table 3. Genetic $\left(F_{S T}\right)$ and phylogeographic structure $\left(\varphi_{S T}\right)$ values of the comparisons among the ten worldwide sampling localities. Structure values are beneath each diagonal and P-values are above them.

\begin{tabular}{|l|l|r|l|l|}
\hline Source of variation & d.f. & $\begin{array}{l}\text { Sum of } \\
\text { squares }\end{array}$ & $\begin{array}{l}\text { Variance } \\
\text { components }\end{array}$ & $\begin{array}{l}\text { Percentage } \\
\text { of variation }\end{array}$ \\
\hline Among groups & 1 & 124.096 & $0.23802 \mathrm{Va}$ & 39.19 \\
\hline Among populations within groups & 8 & 78.725 & $0.11293 \mathrm{Vb}$ & 18.60 \\
\hline Within populations & 1002 & 256.860 & $0.25635 \mathrm{Vc}$ & 48.33 \\
\hline Total & 1011 & 459.681 & 0.6073 & \\
\hline
\end{tabular}

Table 4. Results of the AMOVA among both subspecies of long-finned pilot whales in the South Pacific (i.e. G. m. edwardii) and North Atlantic with the Mediterranean (i.e. G. m. melas).

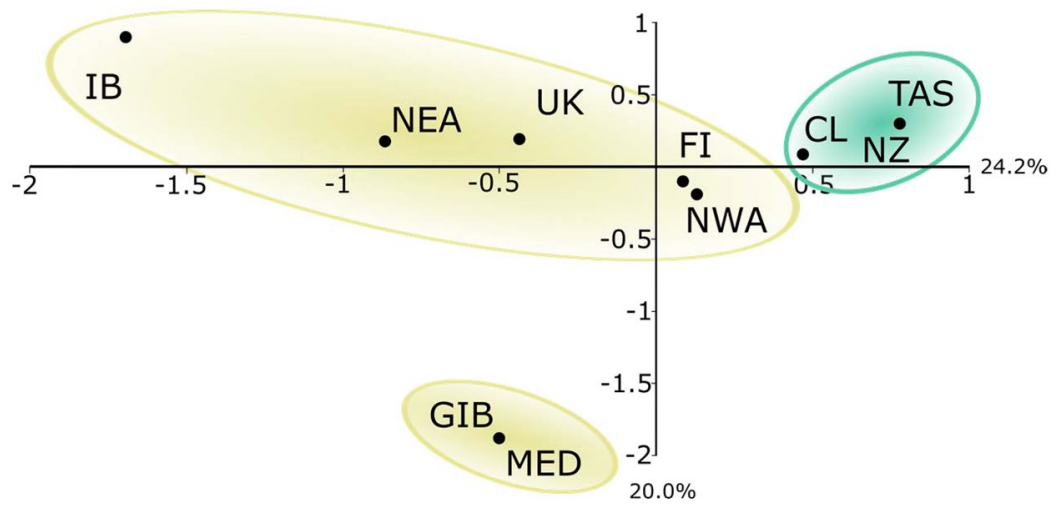

Figure 3. (a) Correspondence Analysis scatter plot of presence/absence of haplotypes per locality: Tasmania (TAS), New Zealand (NZ), Chile (CL), northwestern Atlantic (NWA), Faroe Islands (FI), United Kingdom (UK), Iberian Peninsula (IB), northeastern Atlantic (NEA), Strait of Gibraltar (GIB) and the Mediterranean Sea (MED). Localities within the distribution of G. m. melas are encircled in yellow and the South Pacific localities of G. m. edwardii in green.

our database of 44 analysed individuals from the southeastern Pacific (464/465 and EV37), with 9 and 15 alleles in total. The upper-tail exact test among the five shared loci of G. m. edwardii ${ }^{27}$ and G. m. melas ${ }^{28}$ showed that South Pacific samples had significantly more alleles per locus $(\mathrm{p}=0.028)$. By contrast, the upper-tail exact test 


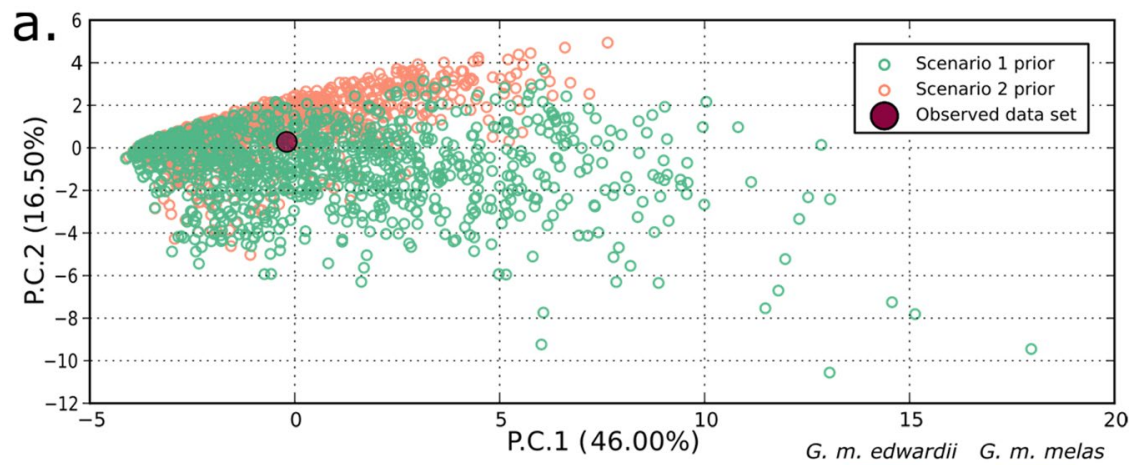

b.

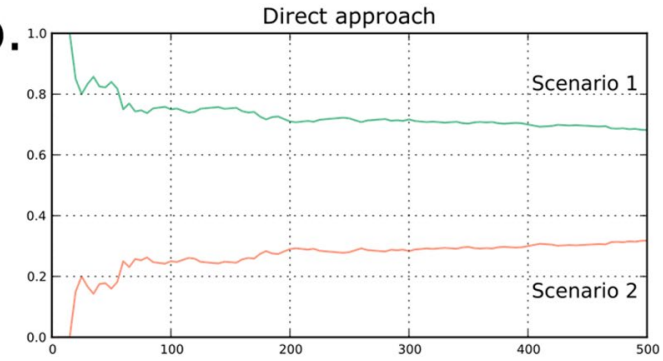

C.

m.

Figure 4. (a) PCA showing the scenario and prior combinations of scenario 1 (green) and scenario 2 (orange); (b) Estimates of posterior probability of scenarios, via direct approach over the closest 500 scenarios; (c) representation of the supported historical biogeographic scenario of colonization.

performed with the 10 loci shared between G. m. edwardii from the southwestern ${ }^{27}$ and southeastern Pacific (this study) did not detect a statistically significant difference $(\mathrm{p}=0.166)$.

\section{Discussion}

Sampling cetacean species for population genetic studies has proven to be logistically challenging. A large number of individuals need to be sampled for this kind of studies, but they are generally widespread geographically and low in density. Mass strandings of cetaceans represent unique opportunities to collect large numbers of samples, as in the case of the franciscana Pontoporia blainville ${ }^{29}$, bottlenose dolphin Tursiops truncatus ${ }^{30}$, Cuvier's beaked whale Ziphius cavirostris ${ }^{31}$ and the short-beaked common dolphin Delphinus delphis ${ }^{32}$. The long-finned pilot whale is a species for which almost all genetic data has been obtained from sampling mass strandings. A large part of its distribution range has been already sampled in the northwestern and northeastern Atlantic ${ }^{23-26}$, but within their broader distribution in the Southern Hemisphere, only the southwestern Pacific has been covered ${ }^{20}$. This study presents new data from two recent mass standings in southern Chile, in order to produce the first genetic information for Globicephala melas in the southeastern Pacific and to integrate this new information into the global phylogeography of the species.

Contrasting tissue quality was found between both strandings, which we attribute to the time of sampling of each event. Our sampling of the Isla Clemente stranding took place an estimated two to three months after occurring $^{33}$, while the Isla Navarino individuals were sampled five days after stranding ${ }^{34}$, precluding tissue the deterioration encountered in the former event. This highlights the importance of swift responses to stranding events, in order to secure the best tissue quality possible.

Prior to conducting mtDNA analyses, we first decided to remove one polymorphic site that exhibited a strong homoplasy signal. This problem in mtDNA sequences of $G$. melas was already detected ${ }^{20}$, but not taken into account for the genetic analyses. Homoplasic sites have been described to hinder the resolution of mtDNA gene trees $^{35}$ and have also been pointed out as potential confounders of evolutionary analysis in the mtDNA control region of humpback whales ${ }^{36}$ and human mtDNA coding regions $s^{37}$, among others.

Despite the addition of 90 new sequences from the southeastern Pacific to the set of available sequences in the literature -over $9000 \mathrm{~km}$ from New Zealand, the nearest sampled locality- the global haplotype network was expanded by just one private low-frequency haplotype, further confirming the worldwide low mitochondrial diversity of $G$. melas. Such low mtDNA diversity has been reported for other matrilineal odontocetes, including orcas $(\pi=0.52 \%)^{38}$, false killer whales $(\pi=0.01-0.30 \%)^{39}$ and sperm whales $(\pi=0.131-0.407 \%)^{40}$. In contrast, cetaceans with more labile social cohesion such as mysticetes and non-matrilineal odontocetes, generally present much higher nucleotide diversity, a feature that appears to be common among these species ${ }^{41}$. Cultural hitchhiking has been regarded as a driver of their low mitochondrial diversity ${ }^{41,42}$. An analogous effect of behaviour on mitochondrial diversity was described in a resident coastal bottlenose dolphin population in central Chile $\mathrm{e}^{43}$. This particular population operates akin to pilot whales as it is also composed of adult females and their descendants, both male and female. That study found that the genetic diversity of this matrilineal population $(\mathrm{Hd}=0.63$; $\pi=0.8 \%)$ was lower than that of the non-matrilineal transient-pelagic group adjacent to them $(\mathrm{Hd}=0.95$; 


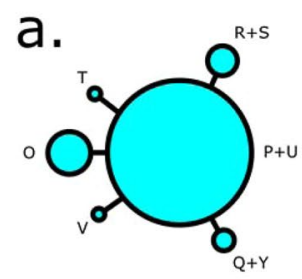

C.
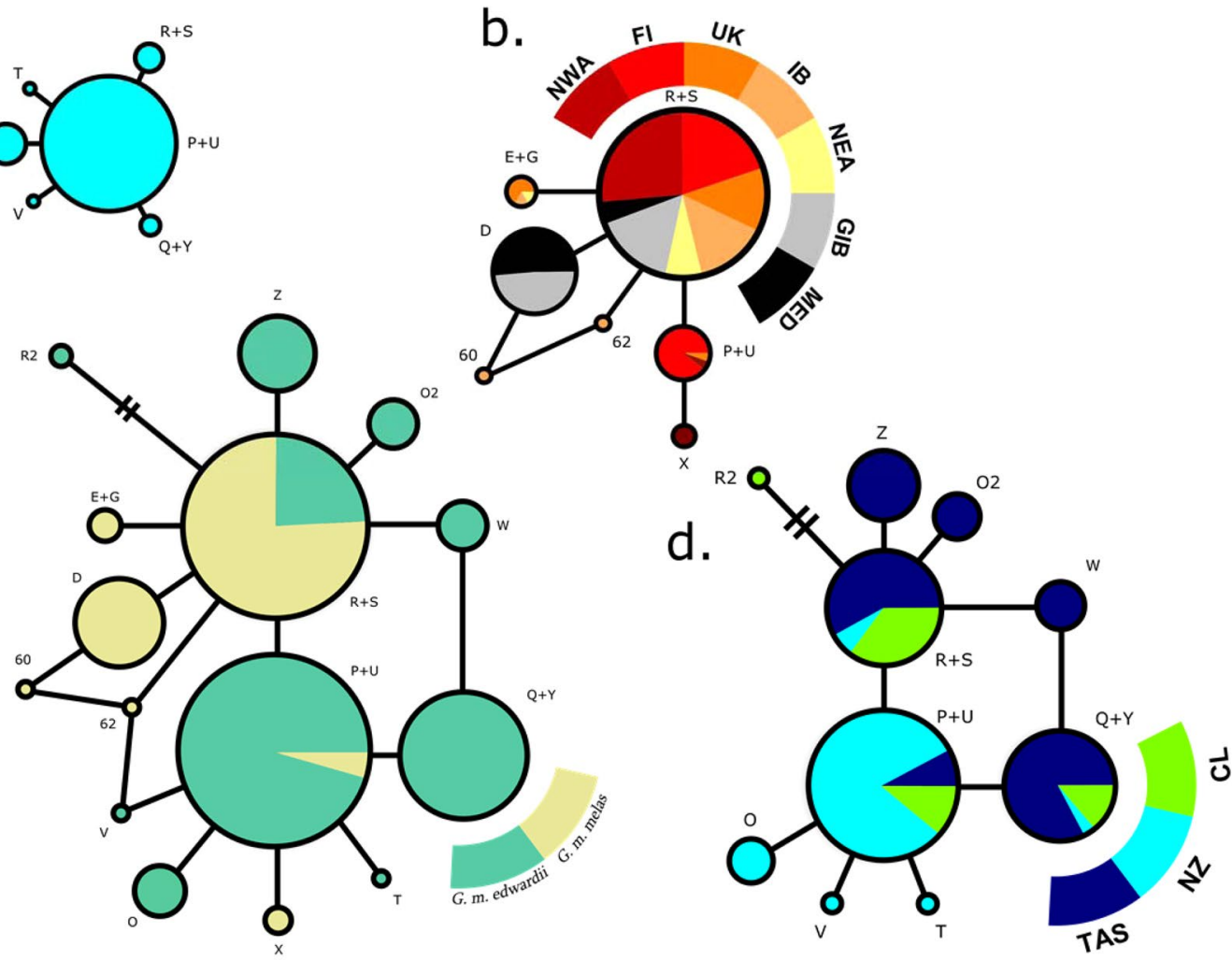

Figure 5. Haplotype networks of (a) New Zealand samples, (b) North Atlantic and Mediterranean samples, (c) Global dataset coloured by subspecies and (d) South Pacific samples. Smallest circle size indicates a frequency of one sequence. Included localities are Tasmania (TAS), New Zealand (NZ), Chile (CL), northwestern Atlantic (NWA), Faroe Islands (FI), United Kingdom (UK), Iberian Peninsula (IB), northeastern Atlantic (NEA), Strait of Gibraltar (GIB) and the Mediterranean Sea (MED). Detailed haplotype frequencies can be found in Table 1.

$\pi=1.4 \%$ ), suggesting the importance of social structure in shaping the pattern of genetic diversity in cetaceans (at least in odontocetes).

As previously reported for other areas ${ }^{20,23,24,26}$, our results show that southeastern Pacific long-finned pilot whales $(n=90)$ have low genetic diversity, in particular for haplotype richness $(h=4)$ and nucleotide diversity ( $\pi=0.23 \%$, Table 1$)$. Within the South Pacific, the diversity indices of southeastern Pacific (i.e. Chilean) samples were similar to the values obtained for Tasmania. Nevertheless, genetic diversity in these two localities was very different from that of New Zealand. Despite accounting for 54\% of the samples in this basin, the genetic and nucleotide diversity of pilot whales from New Zealand were the lowest (Table 1), particularly because of the high predominance of one haplotype ( $93 \%$, haplotype $\mathrm{P}+\mathrm{U})$. Such overrepresentation of a single haplotype in a matrilineal species may derive from sampling bias, for example, by sampling a single, large mass stranding event. However, in that study, the sampling period spanned from 1993 to 2007 and included numerous single and mass strandings that took place in various localities ${ }^{20}$. Therefore, we can assume that this diversity accurately reflects what is present in this area. The distinctiveness of New Zealand from Tasmania and Chile is further supported by high $\varphi_{S T}$ values ( $\varphi_{S T}=0.421$ and 0.342 respectively) (Table 3 ), which are four and five times higher than between Chile and Tasmania $\left(\varphi_{S T}=0.086\right)$. The absence of obvious geographic or oceanographic barriers between New Zealand and the other localities in the South Pacific does not allow a simple interpretation of the pattern of genetic structure found here. This genetic differentiation could have been attained through ecological specialization, as previously pointed out ${ }^{20}$. Similarly, sea surface temperature and its influence on prey distribution has been regarded as a possible ecological factor underlying genetic differentiation in extant G. melas in North Atlantic waters ${ }^{28}$ and similar trends have been observed on the Scotian shelf ${ }^{44}$.

Differentiation over relatively short distances without any conspicuous geographical barriers has also been detected in other odontocetes. For example, genetic differentiation was detected in the Chilean dolphin Cephalorhynchus eutropia between two differing coastal habitats along the uninterrupted Chilean coastline, attributed to habitat adaptation and specific hunting strategies ${ }^{45}$. Also, the Eastern Pacific Barrier has been proposed as a driver behind the genetic differentiation of the short-finned pilot whale Globicephala macrorhynchus into two subspecies ${ }^{46}$.

The haplotype network of the specimens from New Zealand presents a typical star-like shape (Fig. 5a), suggesting that long-finned pilot whales around New Zealand represent a young population, perhaps tracing back to the Last Glacial Maximum, as suggested by DIYABC analyses. During this period, a $6-10^{\circ} \mathrm{C}$ cooling occurred in superficial waters of southeast New Zealand, the strongest temperature drop reported in this area of the southwestern Pacific ${ }^{47}$. Such changes in environmental conditions, probably associated to a shift in the distribution 
of marine biota, may have provoked a typical population contraction-expansion in the long-finned pilot whale population in this area, as described for cold-temperate and polar marine species ${ }^{48}$, including cetaceans ${ }^{49,50}$.

A similar case of strong genetic differentiation among populations of long-finned pilot whales is observed between the North Atlantic and Mediterranean populations, where the latter exhibits high phylogeographic and genetic differences with the North Atlantic localities ${ }^{25}$. In this case, geographic and oceanographic discontinuities between the Mediterranean Sea and the Atlantic Ocean provide a robust explanation for the observed genetic structure. The separation of Mediterranean populations from North Atlantic ones has been previously reported in various marine species, such as shallow water crustaceans $s^{51}$, sea stars ${ }^{52}$, white sharks ${ }^{53}$ and other odontocetes, like in sperm whales ${ }^{54}$, striped dolphins Stenella coeruleoalb ${ }^{55}$ as well as Cuvier's beaked whales Ziphius cavirostris ${ }^{31}$ and Risso's dolphins Grampus griseus ${ }^{56}$.

Widespread cetacean taxa occurring in both the Northern and Southern Hemispheres generally exhibit strong phylogeographic structure and genetic divergence between regions. Such genetic differentiation has been generally exemplified by fixed substitutions in mtDNA control region sequences. This is the case of the fin whale Balaenoptera physalus, with one fixed difference between South and North Atlantic samples, thus presenting no shared haplotypes ${ }^{57}$, the harbour porpoise Phocoena phocoena, with high divergence among ocean basins ${ }^{58}$ and the more closely related false killer whale Pseudorca crassidens ${ }^{39}$. In the latter species, although the study had a low sample size in the North Atlantic, no shared haplotypes were found and at least 10 substitutions separated the Atlantic populations from those in the Indo-Pacific. In the case of G. melas, despite its antitropical distribution and the large geographic discontinuity between northern and southern distribution areas, the subspecies shared their two most abundant haplotypes. This genetic pattern may reflect (1) contemporary gene flow between hemispheres, or alternatively (2) an ancestral polymorphism resulting from an incipient divergence process. The strong phylogeographic structure detected among the subspecies supports the second hypothesis.

The South Pacific network holds much of the species' genetic diversity and is therefore very similar to the global network in overall shape (Fig. 5b). In contrast, the star-like haplotype network of North Atlantic and Mediterranean samples is typically presented by recently expanding populations. A biogeographic scenario of a dispersal event over the equator during previous glacial period has been proposed ${ }^{22}$, with a split in distribution occurred after the Last Glacial Maximum, 10 000-15 000 years ago. This hypothesis was further expanded ${ }^{20}$, mentioning that a trans-equatorial dispersal event rather than vicariance might have taken place, on account of the lower diversity in the Northern Hemisphere subspecies. Thus, the hypothesis is supported by (1) the contrasting haplotype networks (Fig. 5c, d), (2) the higher mitochondrial and microsatellite diversity indices of South Pacific long-finned pilot whales compared to their counterparts in the North Atlantic and Mediterranean (Tables 1 and 2) and (3) the clear separation of areas by hemisphere in the haplotype presence/absence Correspondence Analysis (Fig. 3). The validity of the previously proposed scenario of population history was further explored here with DIYABC population history simulations, comparing a founder effect scenario with a vicariance scenario. The patterns of population genetic diversity and structure observed in G. melas were consistent with the data simulated under the former scenario, a trans-equatorial dispersal event followed by divergence (Fig. 4). Posterior estimation of scenario parameters allowed estimating the time at which the different events occurred, setting the dispersal from the Southern Hemisphere to the North Atlantic at around 13000 years ago, followed by a population demographic expansion around 9380 years ago. However, even considering this scenario of divergence, the absence of reciprocal monophyly does not qualify northern and southern G. melas as different Evolutionary Significant Units (ESU) following the criterion of Moritz $(1994)^{21}$. It is likely that not enough time has passed to sort lineages, or some level of gene flow still occurs ${ }^{59}$, as they still share haplotypes, but in differing frequencies ${ }^{20}$. Additionally, net nucleotide divergence $d_{A}$ and Percent Diagnosability (PD) had been previously calculated for the long-finned pilot whale subspecies ${ }^{60}$, obtaining values of $d_{A}=0.00128$ and $\mathrm{PD}=0.84286$. Our calculation of net nucleotide divergence, which included new sequences from the southeastern Pacific and integrated other published sequences from the Northern Hemisphere, resulted in a slightly higher value of $d_{A}=0.00158$, which still is below the proposed subspecies interval ${ }^{61}$. Therefore, addressing them as Demographically Independent Populations (DIP), a transitional state between a panmictic population and separate ESUs ${ }^{59}$ might be more accurate.

Finally, from a conservation perspective, even if genetic analyses do not support the subspecies category, we recommend maintaining their current taxonomic status, since these DIP might be undergoing a recent divergence process which has yet to mature into fully sorted lineages.

\section{Concluding Remarks}

The results here presented should be considered as preliminary evidence, as the use of a single mtDNA marker for phylogeographic and demographic inferences has been deemed problematic before ${ }^{62}$. As previously stated, such molecular studies should include nuclear markers together with mitochondrial DNA, even more when delimitating species and subspecies ${ }^{18}$. However, to date, the mtDNA control region is the only molecular marker for which sequences are available with sufficient sample size from different ocean basins to perform a worldwide phylogeographic study in G. melas $^{26}$. To incorporate new genetic markers to a global phylogeographic study would require tremendous sampling effort and expenses, and may also strongly depend on the occurrence of mass strandings in all these regions of the world.

Finally, we believe that collaborative studies surveying uncharted areas, especially within the greater distribution range of long-finned pilot whales in the Southern Hemisphere, are fundamental to obtain complete data on the worldwide phylogeography and taxonomy of G. melas and to lay the groundwork for future research on these topics. Modern genetic tools, such as complete mitogenome and SNPs, have been already used to revise the taxonomic status of short-finned pilot whales ${ }^{46}$, which could be replicated in long-finned pilot whales. 


\begin{abstract}
Methods
Southeastern pacific sample collection. Tissue samples were collected from twelve individuals in a stranding event that occurred in Isla Navarino in 2006 (55 $5^{\circ} 15^{\prime} \mathrm{S} ; 67^{\circ} 30^{\prime} \mathrm{W}$ (Fig. 1). In 2016, 124 Globicephala melas were sampled from the mass stranding event that occurred in Isla Clemente $45^{\circ} 35^{\prime} 57.50^{\prime \prime} \mathrm{S} ; 74^{\circ} 34^{\prime} 30.32^{\prime \prime} \mathrm{W}$. All samples were preserved in $90-95 \%$ ethanol.
\end{abstract}

DNA extraction, mitochondrial control region sequencing and microsatellite genotyping. DNA extractions were performed following a modified salt-extraction protocol ${ }^{63}$, adding a second step of digestion with proteinase $\mathrm{K}$ one hour after the first one.

Mitochondrial control region data. The mtDNA control region was amplified using the primers M13 Dlp1.5 5'-TGTAAAACGACAGCCAGTTCACCCAAAGCTG RARTTCTA-3' (forward) and 8 G $5^{\prime}$-GGAGTACTATGTCCTGTAACCA-3' (reverse) $^{31}$. The amplification protocol was as follows: $25.6 \mu \mathrm{L}$ reaction volume for each PCR reaction consisted of $12.7 \mu \mathrm{L}$ water, $5 \mu \mathrm{L} 10 \mathrm{X}$ Buffer (Invitrogen), $2 \mu \mathrm{L} 50 \mathrm{mM} \mathrm{MgCl}{ }_{2}$ (Invitrogen), $2 \mu \mathrm{L} 10 \mathrm{pM}$ dNTPs (Invitrogen), $1 \mu \mathrm{L} 10 \mathrm{pM}$ of each primer $(2 \mu \mathrm{L}$ total), $0.5 \mu \mathrm{L}$ Taq polymerase (Invitrogen) and 70-150 ng of DNA. A Thermo Hybaid PxE 0.5 thermal cycler was used for all amplifications, with the following profile: Preliminary denaturation of 2 minutes at $94^{\circ} \mathrm{C}$; followed by 30 cycles of: denaturation for $30 \mathrm{~s}$ at $94^{\circ} \mathrm{C}$, annealing for $40 \mathrm{~s}$ at $56^{\circ} \mathrm{C}$, polymerase extension for $40 \mathrm{~s}$ at $72^{\circ} \mathrm{C}$; and a final polymerase extension for 10 minutes at $72^{\circ} \mathrm{C}$ and an infinite hold temperature of $4^{\circ} \mathrm{C}$. Each PCR run included positive and negative controls. Fragments were run in a $1 \%$ agarose gel, each well containing $3 \mu \mathrm{L}$ of PCR product mixed with an equal volume of loading dye with $0.3 \% \mathrm{Gel}$ Red and visualized in a gel documentation system (Maestrogen SMU-01).

PCR product purification and sequencing in both directions were done at Macrogen Inc., Seoul, South Korea with a 3730XL DNA Analyzer (Applied Biosystems). All sequences obtained were aligned manually in ProSeq $3.5^{64}$ and polymorphic sites were visually checked. Prior to molecular analyses, the species for each sample was corroborated with two platforms of comparative analysis of sequences: BLAST (Basic Local Alignment Search Tool, www.blast.ncbi.nlm.nih.gov) and DNA Surveillance ${ }^{65}$.

An additional 922 control region sequences were obtained from five other sources: (1) Oremus et al., $(2009)^{20}$ ( $n=573$, Tasmania and New Zealand, GenBank access codes: FJ513342-54); (2) Siemann $(1994)^{26}(\mathrm{n}=59$; western North Atlantic, Cape Cod, Newfoundland, Nova Scotia, Scotland and England; GenBank access codes: U20926-28); (3) Monteiro (2013) $)^{24}(\mathrm{n}=116$, eastern coast of the United States, Faroe Islands, United Kingdom and Iberian Peninsula, GenBank access codes: KC934932-34); (4) Verborgh (2015) ${ }^{25}(\mathrm{n}=117$, eastern coast of the United States, Faroe Islands, United Kingdom, Euskadi, northeastern Atlantic, Iberian Peninsula, Strait of Gibraltar and the Mediterranean Sea; haplotypes reconstructed by hand) and (5) Miralles et al., $(2016)^{23}(\mathrm{n}=57$, Faroe Islands and Iberian Peninsula, GenBank access codes: KJ740360-71) (Table 1).

Sample grouping. Samples were grouped in two ways: (1) first in ten groups, according to their respective sampling locality: Tasmania (TAS), New Zealand (NZ), Chile (CL), northwestern Atlantic (NWA), Faroe Islands (FI), United Kingdom (UK), Iberian Peninsula (IB), northeastern Atlantic (NEA), Strait of Gibraltar (GIB) and the Mediterranean Sea (MED). NEA included samples ranging from UK to IB, and was combined with the locality Euskadi from the original study, since no significant $F_{S T}$ structure was detected among them in that study ${ }^{25}$ (Fig. 1, Table 1). (2) The second way of grouping samples was according to the subspecies categories, i.e. G. m. edwardii from the South Pacific (SP) including the localities TAS, NZ and CL and G. m. melas from the North Atlantic (NA), including NWA, FI, UK, IB, NEA and the Mediterranean (GIB and MED).

Sequence editing. After alignment and trimming, a haplotype network was constructed in Network $5.0^{66}$. With an exploratory examination of the global haplotype network, it was noted that site 156 of the alignment generated three loops in the network. This hypervariable site was considered to be interfering with the phylogeographic signal of the data and was consequently removed, in order to eliminate a potential homoplasy signal. Additionally, a repeated TA motif starting at position 90 was identified as a possible microsatellite. We modified the sequences by deleting one of the nucleotide positions within each repeat, so each motif was considered as a single mutational step, instead of each nucleotide separately. Thus the final fragment length was of $345 \mathrm{bp}$.

Genetic diversity and structure. The genetic diversity indices number of haplotypes (h), number of polymorphic sites (S), haplotype diversity $(\mathrm{Hd})$, nucleotide diversity $(\pi)$ and pairwise differences between sequences (П) were estimated in Arlequin v3.5.267. Analyses of genetic structure $\left(F_{S T}\right)$, phylogeographic structure $\left(\varphi_{S T}\right)$ and analysis of molecular variance (AMOVA) were conducted in Arlequin v3.5.2 with 1000 permutations and a significance level of 0.05. Phylogeographic structure was also explored with Snn tests of genetic differentiation ${ }^{68}$, performed in DnaSP 5.10.0169. For the AMOVA, the ten localities were grouped according to the distribution of each subspecies. A Correspondence Analysis (CA) was performed on all localities with the software Past 3.1970, using the matrix of Table 1 in the form of presence/absence of haplotypes.

Additionally, as suggested by the guidelines for the delimitation of cetacean subspecies using genetic data of Taylor et al. ${ }^{61}$, Nei's (1987) net nucleotide divergence $\left(d_{A} \text {, equation } 10.21\right)^{71}$ was calculated among the two putative subspecies in DnaSP. According to these guidelines, the net nucleotide divergence among two subspecies should be within the range of $d_{A}=0.004-0.04$.

Historical biogeography. The population history of the species was tested on the program DIYABC $\mathrm{v} 2.1 .0^{72}$. This software evaluates population histories using Approximate Bayesian Computation (ABC) with genetic data, by testing scenarios built through the combination of population divergence, admixture and population size changes. Two models were evaluated. The first model was defined based on a scenario previously proposed $^{22}$, together with evidence from the genetic results provided in the present study. The model considers 


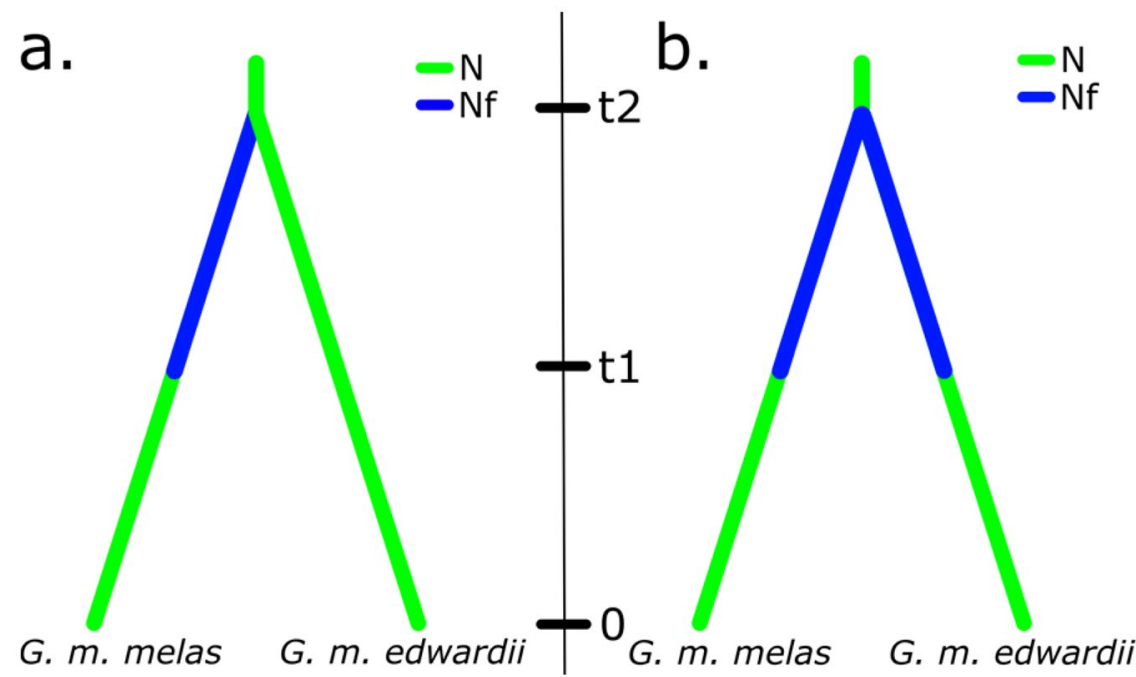

Figure 6. Proposed historical biogeographic scenarios tested in DIYABC: (a) trans-equatorial colonization event followed by divergence and (b) vicariance event. $\mathrm{N}=$ Previous effective population size, $N_{f}=$ founder effect effective population size. Time scale: $0=$ present, $t_{1}=$ population size expansion, $t_{2}=\mathrm{a}$. colonization event or b. population split.

a trans-equatorial, Last Glacial Maximum (LGM)-associated dispersal event from the Southern Hemisphere to the Northern Hemisphere, followed by a split in distribution and instantaneous population growth (Fig. 6). The alternative model differs from the previous one in that it considers a vicariance event, rather than a founder effect. The program was used to evaluate the accordance of these two scenarios with our genetic data. Priors were set as follows: Effective population size $\left(N_{e}\right)$ of ancient population $=1000-100000$; Effective population size of founder effect $\left(N_{f}\right)=10-1000$; time of dispersal event $t_{2}=10000-35000$; time of instantaneous population growth $t_{1}=2$ 000-15000 (with $t_{2}>t_{1}$ ) and mutation rate $\mathrm{u}=1.5 \mathrm{e}^{-7}-1.5 \mathrm{e}^{-8}$. In accordance with the recommendations of the authors of the software, we performed 6000000 simulations.

Microsatellite data. A total of 19 loci were amplified: 409/470, 464/465 73 , DlrFCB1, DlrFCB6 ${ }^{74}$, Ev1, Ev14, EV $37^{75}$, GATA53 ${ }^{76}$, GT6, GT51 ${ }^{77}$, GT23, GT211, GT509, GT575 ${ }^{78}$, MK5, MK9 ${ }^{79}$ and PPHO131 ${ }^{58}$. PCR reactions were done with a Multiplex PCR kit (Qiagen), each reaction containing: $12.5 \mu \mathrm{L}$ of water, $5 \mu \mathrm{L}$ of MM2x Buffer and $1 \mu \mathrm{L}$ of each primer at $10 \mathrm{pM}$. Between two and four loci with different fluorescent dyes were combined in each reaction. Allele scoring was done with the software GeneMarker v2.6.0 (www.softgenetics.com) with a $500 \mathrm{liz}$ standard. The dataset was tested for scoring errors, allele dropout and null alleles in Micro-Checker v.2.2.3 ${ }^{80}$. Observed heterozygosity $\left(H_{o}\right)$, expected heterozygosity $\left(H_{e}\right)$, average number of alleles per locus (nA) and genetic structure $\left(F_{S T}\right)$ were estimated in Genetix v4.05.2 ${ }^{81}$. Published microsatellite data on this species was available from Tasmania and New Zealand ${ }^{27}$, NWA, UK ${ }^{28}$, Faroe Island ${ }^{23,28}$, Iberian Peninsula ${ }^{23}$, northeastern Atlantic, Strait of Gibraltar and the Mediterranean ${ }^{25}$. However, because of the differences in the loci used in these studies, only a partial comparison of genetic diversity could be performed between populations of G. m. melas and G. m. edwardii. Only comparisons of allelic richness could be done, which were carried out in Rundom Pro $1.1^{82}$ with 10000 randomizations. Comparisons were intra-subspecies among southwestern and southeastern Pacific samples, and inter-subspecies among southwestern Pacific and North Atlantic samples.

Approval. We confirm that all methods were carried out in accordance with relevant guidelines and regulations. Samples were taken from stranded, deceased animals with permission from the National Fisheries Service (SERNAPESCA, document ID 2016-11-13). All experimental protocols were approved by the Postgraduate Evaluation Committee at the Faculty of Science of the Universidad de Chile.

Accession codes. Haplotype R2 (GenBank accession number pending. Submission number \#2305260).

Received: 14 May 2019; Accepted: 6 January 2020;

Published online: 04 February 2020

\section{References}

1. Whitehead, H. Sperm whale Physeter macrocephalus. In Würsig, B. G., Thewissen, J. G. M. \& Kovacs, K. M. (eds.) Encyclopedia of marine mammals, 919-925, $3^{\text {rd }}$ edition (Academic Press, an imprint of Elsevier, London, United Kingdom; San Diego, CA, United States, 2018).

2. Ford, J. K. Killer whale Orcinus orca. In Würsig, B. G., Thewissen, J. G. M. \& Kovacs, K. M. (eds.) Encyclopedia of marine mammals, 531-537, $3^{\text {rd }}$ edition. (Academic Press, an imprint of Elsevier, London, United Kingdom; San Diego, CA, United States, 2018).

3. Rojas-Bracho, L., Jaramillo-Legorreta, A. M., Nieto-García, E. \& Cárdenas-Hinojosa, G. Vaquita, Phocoena sinus. In Würsig, B. G., Thewissen, J. G. M. \& Kovacs, K. M. (eds.) Encyclopedia of marine mammals, 1031-1035, $3^{\text {rd }}$ edition. (Academic Press, an imprint of Elsevier, London, United Kingdom; San Diego, CA, United States, 2018). 
4. LeDuc, R. Biogepgraphy. In Würsig, B. G., Thewissen, J. G. M. \& Kovacs, K. M. (eds.) Encyclopedia of marine mammals, 99-103, $3^{\text {rd }}$ edition. (Academic Press, an imprint of Elsevier, London, United Kingdom; San Diego, CA, United States, 2018).

5. Kenney, R. D. Right Whales. In Würsig, B. G., Thewissen, J. G. M. \& Kovacs, K. M. (eds.) Encyclopedia of marine mammals, 817-822, $3^{\text {rd }}$ edition. (Academic Press, an imprint of Elsevier, London, United Kingdom; San Diego, CA, United States, 2018).

6. Jefferson, T. A., Leatherwood, S. \& Webber, M. A. Marine mammals of the world (FAO, Rome, 1996).

7. Lipsky, J. D. Right Whale Dolphins (Lissodelphis borealis and L. peronii). In Perrin, W. F., Würsig, B. G. \& Thewissen, J. G. M. (eds.) Encyclopedia of Marine Mammals, $2^{\text {nd }}$ edition. (Academic Press, San Diego, 2002).

8. Olson, P. \& Reilly, S. Pilot Whales. In Perrin, W., Würsig, B. \& Thewissen, H. (eds.) Encyclopedia of Marine Mammals, 898-903, 2 ${ }^{\text {nd }}$ edition. (Academic Press, San Diego, 2002).

9. Kasuya, T. Past occurrence of Globicephala melaena in the Western North Pacific. Scientific report of the Whales Research Institute 27, 95-110 (1975).

10. Frey, A., Crockford, S. J., Meyer, M. \& O'Corry-Crowe, G. M. Genetic analysis of prehistoric marine mammal bones from an ancient aleut village in the southeastern Bering Sea. Biennal Conference on the Biology of Marine Mammals. San Diego, California, 12-16 December (2005).

11. Ottensmeyer, C. A. \& Whitehead, H. Behavioural evidence for social units in long-finned pilot whales. Canadian Journal of Zoology 81, 1327-1338, https://doi.org/10.1139/z03-127 (2003).

12. Bernard, H. \& Reilly, S. Pilot whales Globicephala Lesson, 1828. In Ridgway, S. \& Harrison, R. (eds.) Handbook of marine mammals (Academic Press, San Diego, CA, 1994).

13. Sergeant, D. Mass stranding of toothed whales (Odontoceti) as a population phenomenon. The Scientific Reports of the Whales Research Institute 34, 1-47 (1982).

14. Amos, B., Barrett, J. \& Dover, G. A. Breeding behaviour of pilot whales revealed by DNA fingerprinting. Heredity 67, 49-55 (1991).

15. Rayner, G. Globicephala leucosagmaphora, a new species of the genus Globicephala. The Annals \& Magazine of Natural History. 11, 543-544 (1939).

16. Davies, J. L. The Southern Form of the Pilot Whale. Journal of Mammalogy 41, 29, https://doi.org/10.2307/1376514 (1960).

17. Sergeant, D. On the External Characters of the Blackfish or Pilot Whales (Genus Globicephala). Journal of Mammalogy 43, 395-413, https://doi.org/10.2307/1376948 (1962).

18. Berta, A. \& Churchill, M. Pinniped taxonomy: review of currently recognized species and subspecies, and evidence used for their description: Pinniped taxonomy: evidence for species and subspecies. Mammal Review 42, 207-234, https://doi. org/10.1111/j.1365-2907.2011.00193.x (2012).

19. Marina, T. I., Marchesi, M. C. \& Goodall, R. N. P. Long-finned pilot whale (Globicephala melas, Traill 1809) subspecies in the Atlantic Ocean: Are there differences in their skulls? Marine Mammal Science 35, 660-676, https://doi.org/10.1111/mms.12548 (2018).

20. Oremus, M. et al. Worldwide mitochondrial DNA diversity and phylogeography of pilot whales (Globicephala spp.): Worldwide mtDNA of pilot whales. Biological Journal of the Linnean Society 98, 729-744, https://doi.org/10.1111/j.1095-8312.2009.01325.x (2009).

21. Moritz, C. D. 'Evolutionarily Significant Units' for conservation. Trends in Ecology \&. Evolution 9, 373-375, https://doi.org/10.1016/ 0169-5347(94)90057-4 (1994).

22. Davies, J. L. The Antitropical Factor in Cetacean Speciation. Evolution 17, 107-116, https://doi.org/10.2307/2406339 (1963).

23. Miralles, L., Oremus, M., Silva, M. A., Planes, S. \& Garcia-Vazquez, E. Interspecific Hybridization in Pilot Whales and Asymmetric Genetic Introgression in Northern Globicephala melas under the Scenario of Global Warming. PLOS ONE 11, e0160080, https://doi. org/10.1371/journal.pone.0160080 (2016).

24. Monteiro, S. R. D. S. Population ecology of long-finned pilot whale (Globicephala melas) off the Western coast of the Iberian Peninsula. Ph.D. Thesis, University of Aberdeen (2013).

25. Verborgh, P. Demografía y estructura de las poblaciones de calderones comunes (Globicephala melas) en el Mediterráneo español. Ph.D. Thesis, Universidad de Las Palmas de Gran Canaria, Las Palmas de Gran Canaria, Spain (2015).

26. Siemann, L. Mitochondrial DNA sequence variation in North Atlantic pilot whales, Globicephala melas. Ph.D. Thesis, Massachusetts Institute of Technology, Woods Hole Oceanographic Institution, Woods Hole, Massachusetts, USA (1994).

27. Oremus, M., Gales, R., Kettles, H. \& Baker, C. S. Genetic Evidence of Multiple Matrilines and Spatial Disruption of Kinship Bonds in Mass Strandings of Long-finned Pilot Whales, Globicephala melas. Journal of Heredity 104, 301-311, https://doi.org/10.1093/ jhered/est007 (2013).

28. Fullard, K. J. et al. Population structure of long-finned pilot whales in the North Atlantic: a correlation with sea surface temperature? Molecular Ecology 9, 949-958 (2000).

29. Cunha, H. A. et al. Population Structure of the Endangered Franciscana Dolphin (Pontoporia blainvillei): Reassessing Management Units. PLOS ONE 9, e85633, https://doi.org/10.1371/journal.pone.0085633 (2014).

30. Parsons, K. M., Noble, L. R., Reid, R. J. \& Thompson, P. M. Mitochondrial genetic diversity and population structuring of UK bottlenose dolphins (Tursiops truncatus): is the NE Scotland population demographically and geographically isolated? Biological Conservation 108, 175-182, https://doi.org/10.1016/S0006-3207(02)00103-9 (2002).

31. Dalebout, M. L. et al. Worldwide structure of mtDNA diversity among Cuvier's beaked whales (Ziphius cavirostris): implications for threatened populations. Molecular Ecology 14, 3353-3371, https://doi.org/10.1111/j.1365-294X.2005.02676.x (2005).

32. Viricel, A., Strand, A. E., Rosel, P. E., Ridoux, V. \& Garcia, P. Insights on common dolphin (Delphinus delphis) social organization from genetic analysis of a mass-stranded pod. Behavioral Ecology and Sociobiology 63, 173-185, https://doi.org/10.1007/ s00265008-0648-7 (2008).

33. Alvarado-Rybak, M. et al. A mass stranding event of long-finned pilot whales (Globicephala melas) in southern Chile. Aquatic Mammals 45, 447-455, https://doi.org/10.1578/AM.45.4.2019.447.

34. Mansilla, L., Olavarría, C. \& Vega, M. A. Stomach contents of long-finned pilot whales (Globicephala melas) from southern Chile. Polar Biology 35, 1929-1933, https://doi.org/10.1007/s00300-012-1222-3.

35. McCracken, K. G. \& Sorenson, M. D. Is Homoplasy or Lineage Sorting the Source of Incongruent mtDNA and Nuclear Gene Trees in the Stiff-Tailed Ducks (Nomonyx-Oxyura)? Systematic Biology 54, 35-55, https://doi.org/10.1080/10635150590910249 (2005).

36. Jackson, J. A. et al. Global diversity and oceanic divergence of humpback whales (Megaptera novaeangliae). Proceedings of the Royal Society B: Biological Sciences 281, https://doi.org/10.1098/rspb.2013.3222 (2014).

37. Herrnstadt, C. et al. Reduced-Median-Network Analysis of Complete Mitochondrial DNA Coding-Region Sequences for the Major African, Asian, and European Haplogroups. The American Journal of Human Genetics 70, 1152-1171, https://doi.org/10.1086/339933 (2002)

38. Hoelzel, A. R. et al. Low worldwide genetic diversity in the killer whale (Orcinus orca): implications for demographic history. Proceedings of the Royal Society B: Biological Sciences 269, 1467-1473, https://doi.org/10.1098/rspb.2002.2033 (2002).

39. Martien, K. K. et al. Nuclear and Mitochondrial Patterns of Population Structure in North Pacific False Killer Whales (Pseudorca crassidens). Journal of Heredity 105, 611-626, https://doi.org/10.1093/jhered/esu029 (2014).

40. Alexander, A. et al. What influences the worldwide genetic structure of sperm whales (Physeter macrocephalus)? Mol. Ecol. 25, 2754-2772, https://doi.org/10.1111/mec.13638 (2016).

41. Whitehead, H., Vachon, F. \& Frasier, T. R. Cultural Hitchhiking in the Matrilineal Whales. Behavioral. Genetics 47, 324-334, https:// doi.org/10.1007/s10519-017-9840-8 (2017). 
42. Whitehead, H. Genetic diversity in the matrilineal whales: models of cultural hitchhiking and group-specific non-heritable demographic variation. Marine Mammal Science 21, 58-79, https://doi.org/10.1111/j.1748-7692.2005.tb01208.x (2005).

43. Pérez-Alvarez, M. J. et al. Home sweet home: social dynamics and genetic variation of a long-term resident bottlenose dolphin population off the Chilean coast. Animal Behavior. 139, 81-89, https://doi.org/10.1016/j.anbehav.2018.03.009 (2018).

44. Gowans, S. \& Whitehead, H. Distribution and habitat partitioning by small odontocetes in the Gully, a submarine canyon on the Scotian Shelf. Canadian Journal of Zoology 73, 1599-1608, https://doi.org/10.1139/z95-190 (1995).

45. Pérez-Alvarez, M. J. et al. Microsatellite Markers Reveal Strong Genetic Structure in the Endemic Chilean Dolphin. PLOS ONE 10, e0123956, https://doi.org/10.1371/journal.pone.0123956 (2015).

46. Van Cise, A. M. et al. Oceanographic barriers, divergence, and admixture: Phylogeography and taxonomy of two putative subspecies of short-finned pilot whale. Molecular Ecology 28, 2886-2902, https://doi.org/10.1111/mec.15107.

47. Barrows, T. T., Juggins, S., De Deckker, P., Thiede, J. \& Martinez, J. I. Sea-surface temperatures of the southwest Pacific Ocean during the Last Glacial Maximum. Paleoceanography 15, 95-109, https://doi.org/10.1029/1999PA900047 (2000).

48. Marko, P. B. et al. The 'Expansion-Contraction' model of Pleistocene biogeography: rocky shores suffer a sea change? Molecular Ecology 19, 146-169, https://doi.org/10.1111/j.1365-294X.2009.04417.x (2010).

49. O'Corry-Crowe, G. Climate change and the molecular ecology of arctic marine mammals. Ecological Applications 18, S56-S76, https://doi.org/10.1890/06-0795.1 (2008).

50. Pérez-Alvarez, M. J. et al. Historical dimensions of population structure in a continuously distributed marine species: The case of the endemic Chilean dolphin. Scientific Reports 6, https://doi.org/10.1038/srep35507 (2016).

51. García-Merchán, V. H. et al. Phylogeographic patterns of decapod crustaceans at the Atlantic-Mediterranean transition. Molecular Phylogenetics and Evolution 62, 664-672, https://doi.org/10.1016/j.ympev.2011.11.009 (2012).

52. Baus, E., Darrock, D. J. \& Bruford, M. W. Gene-flow patterns in Atlantic and Mediterranean populations of the Lusitanian sea star Asterina gibbosa. Molecular Ecology 14, 3373-3382, https://doi.org/10.1111/j.1365-294X.2005.02681.x (2005).

53. O'Leary, S. J. et al. Genetic Diversity of White Sharks, Carcharodon carcharias, in the Northwest Atlantic and Southern Africa. Journal of Heredity 106, 258-265, https://doi.org/10.1093/jhered/esv001 (2015).

54. Drouot, V. et al. A note on genetic isolation of Mediterranean Sperm Whales, Physeter macrocephalus, suggested by mitochondrial DNA. Journal of Cetacean Research and Management 6, 29-32 (2004).

55. Garcia-martinez, J., Moya, A., Raga, J. A. \& Latorre, A. Genetic differentiation in the striped dolphin Stenella coeruleoalba from European waters according to mitochondrial DNA (mtDNA) restriction analysis. Molecular Ecology 8, 1069-1073, https://doi. org/10.1046/j.1365-294x.1999.00672.x (1999).

56. Gaspari, S., Airoldi, S. \& Hoelzel, A. R. Risso's dolphins (Grampus griseus) in UK waters are differentiated from a population in the Mediterranean Sea and genetically less diverse. Conservation Genetics 8, 727-732, https://doi.org/10.1007/s10592-006-9205-y (2007).

57. Archer, F. I. et al. Mitogenomic Phylogenetics of Fin Whales (Balaenoptera physalus spp.): Genetic Evidence for Revision of Subspecies. PLOS ONE 8, e63396, https://doi.org/10.1371/journal.pone.0063396 (2013).

58. Rosel, P. E., France, S. C., Wang, J. Y. \& Kocher, T. D. Genetic structure of harbour porpoise Phocoena phocoena populations in the northwest Atlantic based on mitochondrial and nuclear markers. Molecular Ecology 8, S41-S54, https://doi. org/10.1046/j.1365-294X.1999.00758.x (1999).

59. Morin, P. A. \& Dizon, A. E. Genetics, Management. In Würsig, B. G., Thewissen, J. G. M. \& Kovacs, K. M. (eds.) Encyclopedia of marine mammals, 410-416, $3^{\text {rd }}$ edition. (Academic Press, an imprint of Elsevier, London, United Kingdom; San Diego, CA, United States, 2018).

60. Rosel, P. E. et al. Examining metrics and magnitudes of molecular genetic differentiation used to delimit cetacean subspecies based on mitochondrial DNA control region sequences. Marine Mammal Science 33, 76-100, https://doi.org/10.1111/mms.12410 (2017).

61. Taylor, B. L. et al. Guidelines and quantitative standards to improve consistency in cetacean subspecies and species delimitation relying on molecular genetic data. Marine Mammal Science 33, 132-155, https://doi.org/10.1111/mms.12411.

62. Morin, P. A. et al. Complete mitochondrial genome phylogeographic analysis of killer whales (Orcinus orca) indicates multiple species. Genome Research 20, 908-916, https://doi.org/10.1101/gr.102954.109 (2010).

63. Aljanabi, S. M. \& Martinez, I. Universal and rapid salt-extraction of high quality genomic DNA for PCR-based techniques. Nucleic Acids Research 25, 4692-4693 (1997).

64. Filatov, D. A. Processing and population genetic analysis of multigenic datasets with ProSeq. 3 software. Bioinformatics 25, 3189-3190, https://doi.org/10.1093/bioinformatics/btp572 (2009).

65. Ross, H. A. et al. DNA surveillance: web-based molecular identification of whales, dolphins, and porpoises. Journal of Heredity 94, 111-114 (2003)

66. Bandelt, H. J., Forster, P. \& Röhl, A. Median-joining networks for inferring intraspecific phylogenies. Molecular Biology and Evolution 16, 37-48 (1999).

67. Excoffier, L. \& Lischer, H. E. L. Arlequin suite ver 3.5: a new series of programs to perform population genetics analyses under Linux and Windows. Molecular Ecology Resources 10, 564-567, https://doi.org/10.1111/j.1755-0998.2010.02847.x (2010).

68. Hudson, R. R. A New Statistic for Detecting Genetic Differentiation. Genetics 155, 2011 (2000).

69. Librado, P. \& Rozas, J. DnaSP v5: a software for comprehensive analysis of DNA polymorphism data. Bioinformatics 25, 1451-1452, https://doi.org/10.1093/bioinformatics/btp187 (2009).

70. Hammer, O., Harper, D. A. T. \& Ryan, P. D. Paleontological Statistics Software Package for education and data analysis. Palaeontologia Electronica 4, 9 (2001).

71. Nei, M. Molecular evolutionary genetics (Columbia Univeristy Press, 1987).

72. Cornuet, J.-M. et al. DIYABC v2.0: a software to make approximate Bayesian computation inferences about population history using single nucleotide polymorphism, DNA sequence and microsatellite data. Bioinformatics 30, 1187-1189, https://doi.org/10.1093/ bioinformatics/btt763 (2014).

73. Amos, B., Schlotterer, C. \& Tautz, D. Social structure of pilot whales revealed by analytical DNA profiling. Science 260, 670-672 (1993).

74. Buchanan, F. C., Friesen, M. K., Littlejohn, R. P. \& Clayton, J. W. Microsatellites from the beluga whale Delphinapterus leucas. Molecular Ecology 5, 571-575, https://doi.org/10.1046/j.1365-294X.1996.00109.x (1996).

75. Valsecchi, E. \& Amos, W. Microsatellite markers for the study of cetacean populations. Molecular Ecology 5, 151-156, https://doi. org/10.1111/j.1365-294X.1996.tb00301.x (1996).

76. Palsboll, P. J., Berube, M., Larsen, A. H. \& Jorgensen, H. Primers for the amplification of tri- and tetramer microsatellite loci in baleen whales. Molecular Ecology 6, 893-895, https://doi.org/10.1046/j.1365-294X.1997.d01-214.x (1997).

77. Caldwell, M., Gaines, M. S. \& Hughes, C. R. Eight polymorphic microsatellite loci for bottlenose dolphin and other cetacean species. Molecular Ecology Notes 2, 393-395, https://doi.org/10.1046/j.1471-8286.2002.00270.x (2002).

78. Berube, M., Jörgensen, H., McEwing, R. \& Palsboll, P. J. Polymorphic di-nucleotide microsatellite loci isolated from the humpback whale, Megaptera novaeangliae. Molecular Ecology 9, 2181-2183, https://doi.org/10.1046/j.1365-294X.2000.105315.x (2000).

79. Krützen, M., Valsecchi, E., Connor, R. C. \& Sherwin, W. B. Characterization of microsatellite loci in Tursiops aduncus: Primer note. Molecular Ecology Notes 1, 170-172, https://doi.org/10.1046/j.1471-8278.2001.00065.x (2001).

80. Van Oosterhout, C., Hutchinson, W. F., Wills, D. P. M. \& Shipley, P. micro-checker: software for identifying and correcting genotyping errors in microsatellite data. Molecular Ecology Notes 4, 535-538, https://doi.org/10.1111/j.1471-8286.2004.00684.x (2004). 
81. Belkhir, K., Borsa, P., Chikhi, L., Raufaste, N. \& Bonhomme, F. Genetix 4.05, logiciel sous windows pour la génétique des populations. laboratoire génome, populations, interactions, cnrs umr 5000. Univ. de Montpellier II, Montpellier, France (2004).

82. Jadwiszczak, P. Rundom Projects: an application for randomization and bootstrap testing, version 1.1. Computer program available from the web site http://pjadw.tripod.com. (2003).

\section{Acknowledgements}

We would like to thank the Chilean Navy for providing transportation and personnel for the sampling in Isla Clemente and Beagle Channel, and the National Fisheries Service (SERNAPESCA) for helping and organizing the Isla Clemente expedition and storing and sending the samples to our laboratory in Santiago. We would also like to thank Miguel Iñiguez, Elsa Cabrera, Barbara Galetti (CCC Chile) for the help during the collection of samples in the Isla Navarino stranding and Fundación CEQUA for their support. Funding: Beca CONICYT 2017 de Magister Nacional 22171215, Instituto de Ecología y Biodiversidad (IEB, Proyecto CONICYT PIA APOYO CCTE AFB170008), Proyecto PIA CONICYT ACT172065, Proyecto FONDECYT iniciación 11170182, Proyecto Fortalecimiento de Centros Regionales del Programa Regional CONICYT R16A10003.

\section{Author contributions}

Sample collection: S.K. collected the Isla Clemente samples, C.O. collected the Isla Navarino samples. Laboratory work: S.K. extracted and amplified both mitochondrial and microsatellite markers for the Isla Clemente samples, C.O. extracted and amplified the mitochondrial marker for the Isla Navarino samples. S.K. amplified the microsatellite markers for the Isla Navarino samples. S.K. prepared and analyzed the data and prepared the figures and tables. S.K., M.J.P.A. and E.P. interpreted and discussed the results. All authors reviewed the manuscript.

\section{Competing interests}

The authors declare no competing interests.

\section{Additional information}

Correspondence and requests for materials should be addressed to M.P.-Á.

Reprints and permissions information is available at www.nature.com/reprints.

Publisher's note Springer Nature remains neutral with regard to jurisdictional claims in published maps and institutional affiliations.

Open Access This article is licensed under a Creative Commons Attribution 4.0 International License, which permits use, sharing, adaptation, distribution and reproduction in any medium or format, as long as you give appropriate credit to the original author(s) and the source, provide a link to the Creative Commons license, and indicate if changes were made. The images or other third party material in this article are included in the article's Creative Commons license, unless indicated otherwise in a credit line to the material. If material is not included in the article's Creative Commons license and your intended use is not permitted by statutory regulation or exceeds the permitted use, you will need to obtain permission directly from the copyright holder. To view a copy of this license, visit http://creativecommons.org/licenses/by/4.0/.

(c) The Author(s) 2020 